\title{
The Baikal region as a unified socio-ecological and economic system in the strategy of territorial development of the Russian Federation
}

\author{
Evdokia Dugina , Elena Dorzhieva*, Ouyna Bazarova, and Nadezhda Bulatova \\ East Siberia State Technical University, Kluychevskaya Str., 40V, 670013 Ulan-Ude, Russia
}

\begin{abstract}
The Baikal region, which includes 3 constituent entities in the territory of the Russian Federation - the Republic of Buryatia, the Irkutsk Region and the Trans-Baikal Territory - should be considered due to its location (in the territory of the Lake Baikal drainage basin) and from the point of view of the regional economy as a single socio-ecological and economic system, whose development should be aimed at preserving the unique ecosystem of the deepest lake on the planet. However, in the Territorial Development Strategy of the Russian Federation, the Baikal region is not included in the list of macroregions despite its compliance with the general principles of their formation. In our opinion, the Baikal region is united by a specific mission entrusted to its population - the need to preserve the unique Baikal ecosystem while ensuring a decent level and quality of life for people living in the Baikal natural territory. The article analyzes the need for a transition to an environmentally oriented innovation economy, which allows transforming the "Baikal factor" from a problem that hinders economic growth into a resource for territorial development.
\end{abstract}

\section{Introduction}

The transformation of the country's economic development model in recent years, characterized by the instability of the world economy, the devaluation of traditional doctrines and institutions of global governance, the increasing uncertainty of the international environment and the evolution of the role of international organizations in a changing multipolar world, requires the formation of new approaches to managing development and allocation of productive forces in the territorial social-economic system. However, the approved Territorial Development Strategy of the Russian Federation for the Period up to 2025 (hereinafter referred to as the TDS) was criticized by the expert community for insufficient transparency in making critical decisions, the lack of broad discussion and dialog with representatives of regions, business community, scientists and the public and for the use of command-and-control methods of planning and management in setting priorities, goals and objectives of regional development and developing measures

\footnotetext{
*Corresponding author: elendorg@mail.ru
} 
to achieve them [1]. Numerous debates have sparked over the supposed place and role of agglomerations in territorial development. For example, the TDS emphasizes that most countries are characterized by polycentric development, but in Russia, economic growth is concentrated in a limited number of centers: $75 \%$ of Russian citizens live in cities. The compaction of the country's economic space has led to the fact that $5 \%$ of its territory produces over $40 \%$ of the total GRP, while in the territories of Siberia and the Far East this figure does not even reach $30 \%$ [2]. Outside the agglomerations, at least 60 million people live in Russia, the enlargement of the agglomerations and the resettlement of citizens there will lead to the extinction of small and medium-sized cities, the disappearance of the village, the depopulation of vast spaces (the risks are especially great in the zone of uncomfortable living located north and east of the line Northern Ural - Baikal - Sakhalin). Meanwhile, some regions of Siberia and the Far East belong to geostrategic territories, due to their border location affecting the national security of the Russian Federation.

In addition, while being guided by such principles of allocation of macroregions as the neighboring position of constituent entities, similar natural, climatic and socio-economic conditions, the possibility of implementing large interregional infrastructure projects in their territory, a potential reduction in the transfer burden on the federal budget due to greater economic self-sufficiency (better developed regions will become centers for the development of the territory), the developers of the TDS did not take into account the underdeveloped system of interregional socio-economic ties, threats to regional identity that could lead to a conflict of regional elites, the possible reduction of growth centers as a result of the regional capitals losing their status, which will lead to further compaction of the country's economic space. The relativeness of the boundaries of the selected macroregions was shown by the transfer in 2018 of the Republic of Buryatia and the TransBaikal Territory to the Far Eastern Federal District, which took place as a result of the desire of the regional authorities to use the tools for the development of the economy and social sphere that operate in the Far Eastern regions (advanced development territories, a free port, construction of social infrastructure, free provision of one-hectare land plots in the Far East, etc.). As a result, the provisions of the Strategy for the socio-economic development of the Far East and the Baikal region for the period up to 2025, in force since 2009, have lost their relevance [3].

In our opinion, the Baikal region is not included in the list of macroregions in the TDS for reasons of an internal political nature: promising economic specializations in the Irkutsk Region (IR), the Trans-Baikal Territory (TBT) and the Republic of Buryatia (RB) overlap in many ways. It not only corresponds to the general principles of the formation of macroregions: the neighboring position of the constituent entities, similar natural, climatic and socio-economic conditions, the possibility of implementing large interregional infrastructure projects in the territory, but it is also united by the specific mission entrusted to its population - the need to preserve the unique Baikal ecosystem while ensuring a decent level and quality of life of people living in the Baikal natural territory (BNT).

\section{Materials and Methods}

During the research, abstract-logical, monographic methods, forecasting and planning methods, economic-mathematical, economic-statistical and other methods were used.

The main methods of this study are the analysis and generalization of federal and regional legal acts regulating the development of the constituent entities of the Russian Federation, analysis of macro- and mesoeconomic dynamics, methods of institutionalism and conceptual modeling. 


\section{Results and Discussion}

The Baikal region, which includes 3 constituent entities in the territory of the Russian Federation - the RB, the IR and the TBT - is considered due to its location (in the territory of the Lake Baikal drainage basin) and from the point of view of the regional economy as a single socio-ecological and economic system, whose development should be aimed at preserving the unique ecosystem of the deepest lake on the planet (the share of its territory remaining in the undisturbed "wild" state reaches $81 \%$ ) $[4,5]$. The issues of the ecological development of the Baikal region are of interest to the world community, representatives of government structures both at the federal and regional levels, public organizations, science and business, and their priorities are set in different ways: if at the global level actors are concerned about strategic threats (the projected global deficit of drinking water, clean natural territories, and biological resources), then at the regional and local levels, the current problems are being solved regarding the socio-economic development, improving the level and quality of life of the population, harmonizing stringent environmental requirements and restrictions with the need to conduct competitive economic activities and reduce migration outflow to central and southern regions of the country. From the point of view of modern mankind, Baikal is a unique freshwater ecosystem by world standards, the study of which is of enduring importance for understanding the evolution of life on Earth [6], and Russia bears responsibility for its preservation. The threat of losing the status of Baikal as a World Heritage site determines the policy of the federal leadership of the country for the development of the Baikal territories, the implementation of infrastructure projects, further economic development of the Baikal region, tightening of environmental standards and requirements for resource preservation [7]. As a result, the current strict protection regimes reduce the economic attractiveness of the macroregion, lead to stagnation of lakeside territories, "shrinkage" of the developed space, an increase in the depression of individual municipalities (for example, fishing, which played a significant role in the economic structure and was the main source of income for the population on the lake shore, has mostly moved into the shadow sector after the Ministry of Agriculture had introduced on October 1, 2017 ban on the commercial catch of omul (Coregonus autumnalis), which is a Baikal endemic).

In these conditions, the regional authorities of the three constituent entities of the Russian Federation should pursue a unified policy aimed at ecologically oriented innovative growth of the economy of the Baikal region and taking into account the nature, specificity and uniqueness of the Baikal ecosystem. When developing conceptual approaches to the development of the Baikal region, it should be perceived as a single socio-ecological and economic system that needs a special model of building relations between the state, society and nature, the basis of this model being the balance of interests of all parties involved [8].

The complex of socio-economic and environmental problems accumulated to date makes the region an unattractive place to live, which is clearly demonstrated by the dynamics of the financial and economic results of the IR, the RB, and the TBT (Fig. 1). 


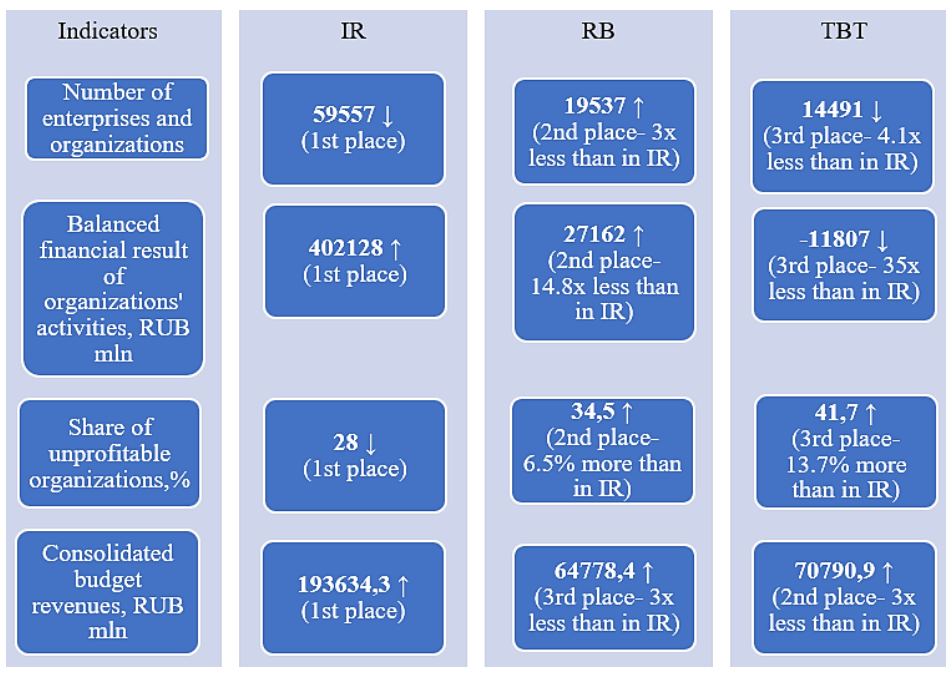

Fig. 1. Dynamics of financial and economic results in the constituent entities of the Baikal region in 2018 (arrows show the direction of change in the values of indicators (increase or decrease compared to 2010 ).

The small population, which affects the size and volume of local sales markets, a significant distance from densely populated areas, whose residents, striving to meet differentiated demands and possessing high purchasing power, are able to provide sustainable demand, negatively affect the growth potential of regional business. The impact of these factors on the level of entrepreneurial activity in Trans-Baikalia aggravates the depressive state of the region's economy.

The leader of the economy of the Baikal region is the IR, the RB is in second place, and the TBT ranks third. In the TDS, the IR is included in the Angara-Yenisei macroregion, which is comprised of the Republics of Tyva, Khakassia, the Krasnoyarsk Territory (taking into account potential projects for the development of territorial-industrial complexes in these territories), while the RB and the TBT are attributed to the Far Eastern macroregion in accordance with the current administrative boundaries, moreover due to their border location, they were included in the list of priority geostrategic territories of the Russian Federation.

And yet, in our opinion, the territorial development must necessarily take into account the regional territorial policy, ethnic characteristics, the prevailing way of life of the people and the interests of the people living in the territory. The specificity of the Baikal region predetermines the need to apply an environmentally oriented approach to the innovative development of the Baikal socio-ecological and economic system.

In official documents defining goals, objectives, main directions of socio-economic development (SED) of the IR, the RB and the TBT, similar conceptual approaches to strategic planning at the regional level are used (Fig. 2). 


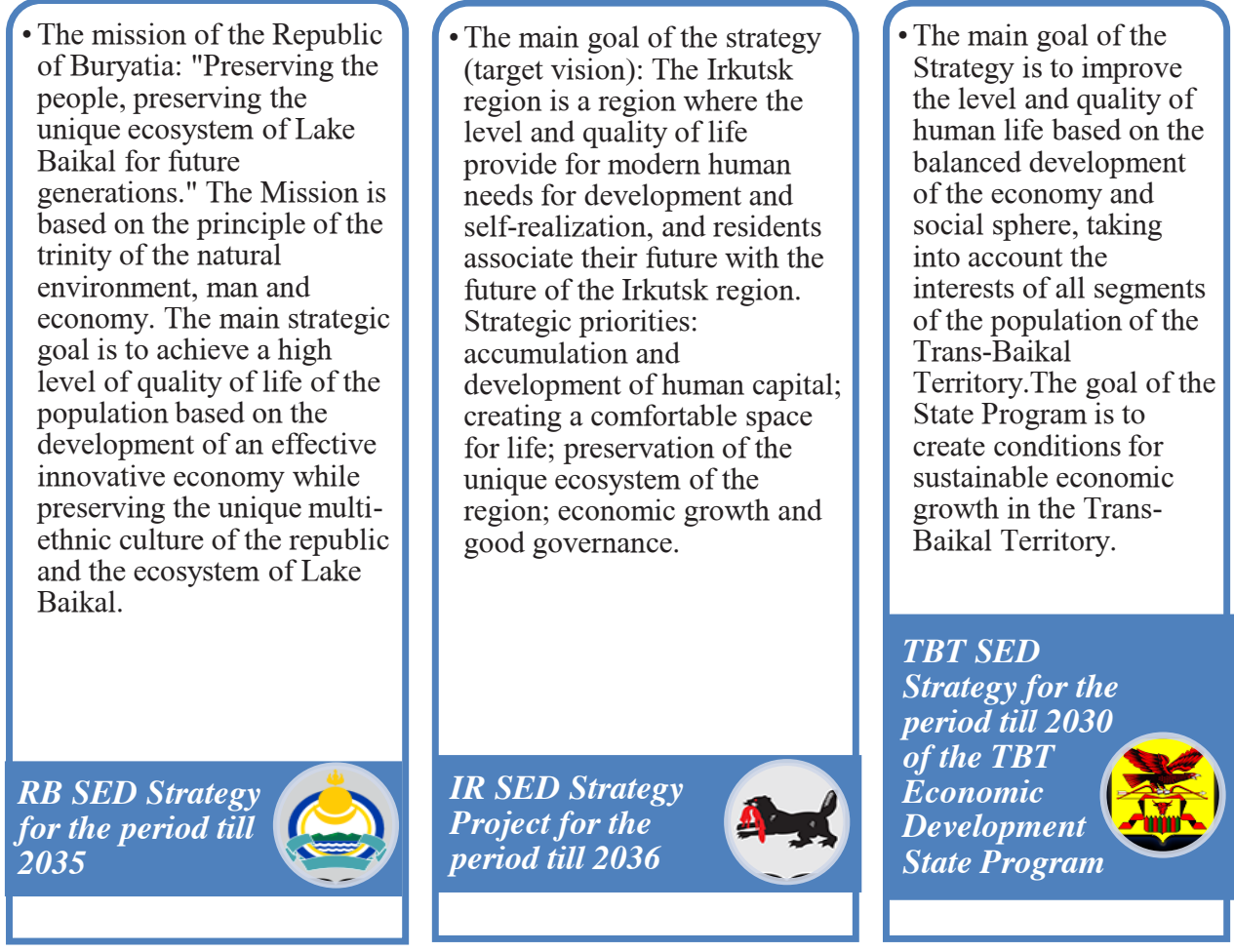

Fig. 2. Goals of long-term socio-economic development of the constituent entities of the Baikal region.

The tasks of the RB and the IR coincide in terms of the formation of an environmentally oriented policy aimed at preserving the Baikal ecosystem. In the Strategy of the SED of the $\mathrm{RB}$, the emphasis is placed on the trinity of man, economy and the natural environment, which should develop in harmony with each other; in the IR the emphasis is placed on an "information man" brought up in the spirit of regional patriotism. In the State Program of Economic Development of the TBT, the goal is formulated too generally and vaguely; as a process, not a result. The promising directions of development of the three regions largely coincide: in all three regions, the tasks are set to develop industrial potential, small and medium-sized businesses, and stimulate investment and innovation.

Since the Baikal region (with the exception of the IR) occupies low places in the Russian Federation in terms of the main socio-economic indicators, and the dubious efficiency of the use of existing social resources is currently unable to attract not only foreign investors, but also actors from other federal districts and constituent entities (regional brands based on ethnic, ecological, cultural ideas, ethno-cultural and confessionalreligious customs and traditions are still in the process of formation; low entrepreneurial activity of the population does not correlate in any way with high values of intellectual potential components; social activity does not affect business and politics of the administration), innovative ecological and economic growth could constitute a promising approach to territorial development, according to the authors. We agree with V.G. Belomestnov that the environmental restrictions associated with the Baikal factor should be considered in the process of strategic planning not from the position of the weakness of the Baikal region, but rather as a unique opportunity to ensure the harmonious development of the Baikal socio-ecological and economic system. "At present, the recreational, tourist and 
food (for renewable bioresources) potential is mainly involved, which is only a small fraction of the potential of ecological resources." [9]

For problem areas (sparsely populated, remote, border, peripheral, characterized by unfavorable natural and climatic conditions, etc.), their limiting factors should become, if not an advantage, then one of the resources of territorial development, allowing to obtain a positive (or neutralize negative) effect from structural disproportions as a result of the implementation of a balanced socio-ecological and economic policy in close mutual coordination with territorial, sectoral and other documents regulating the development of socio-ecological and economic systems at all levels of government.

\section{Conclusions}

Adherence to the traditional regional industrial policy for the Baikal region, taking into account its specifics, is a dead-end development path leading to the destruction of the Baikal ecosystem, the loss of the status of a World Heritage site and the exodus of the population, first from rural settlements to regional centers, and then from overpopulated agglomeration cities to other regions and countries. In terms of life expectancy, the IR is in 80th place in the Russian Federation, the RB is 65th, and the TBT ranks 82nd: this indicator clearly reflects the level and quality of life of the population (environmental situation, development of the social sphere - health care, social security, etc.).

The way out could be in the intensification of environmentally-oriented innovation activities, the transformation of the lake Baikal from an anchor that keeps the region in low positions in national ratings, into a development driver, a source of sustainable competitive advantages, an incentive for the transformation of the Baikal territory into an irreplaceable link in the global economic system, connecting the Euro-Atlantic and Asia-Pacific macroregions.

For this, it is necessary to establish an effective system of interregional relationships and interaction at both the administrative and social levels. However, the study of the program documents regulating the long-term SED of the IR, the RB and the TBT showed that general phrases about the need to activate horizontal cooperation ties with the constituent entities of the Baikal region are not backed by programs to support joint initiatives: in the list of investment projects envisaged for financing until 2030, only measures for the development of transport infrastructure can be called interregional investment projects; they are aimed at the construction and modernization of regional communications.

A promising area of cooperation could be the formation of inter-territorial clusters in those spheres of activity in which the regions have common interests and potential for development that does not cause (or minimizes) damage to the Baikal ecosystem: in the agro-industrial complex, tourism and recreation, and the biotechnology industry [10]. The formation of such clusters will contribute to increasing the connectivity of the Baikal territory and spreading the approach to the development of the Baikal region as a unified socio-ecological and economic system with common economic interests and rational distribution of environmental costs associated with the need to preserve the UNESCO World Natural Heritage site, whose global goal is organic integration into the Russian and world geopolitical space on the basis of creating a comfortable living environment that attracts people, and maintaining the equilibrium state of the Baikal ecosystem for the benefit of present and future generations. 


\section{Acknowledgements}

This work was made within the grant "Young Researchers of the East Siberia State University of Technology and Management" on the topic No. 121040800213-2.

\section{References}

1. Decree of the Government of the Russian Federation. "The spatial development strategy of the Russian Federation for the period until 2025" of 13.02.2019 N 207-r, http://government.ru/ (2019)

2. V. Matviyenko, Izvestia, June 27, 2018 (2018)

3. E. V. Dorzhieva, E. L. Dugina, V. G. Belomestnov, N. N. Bulatova, EpSBS, LXXVII, 356 (2019)

4. A.K. Tulokhonov, A.N. Beshentsev, Geography and Natural Resources, 4, 357 (2017)

5. V.E. Saktoev, V.V. Mantatov, ESSUTM Bulletin, 2, 103 (2010)

6. UNESCO World Heritage, https://whc.unesco.org

7. Baikal Strategies: Intellectual Business Club, Baikal as a trap for world processes, http://frontier.baikstrategy.ru (2019)

8. O. M. Tsybikdorzhiyeva, V. G. Belomestnov, JAES, 2, 412 (2017)

9. O. M. Tsybikdorzhiyeva, V. G. Belomestnov, iSee, 8, 1 (2015)

10. E.L. Dugina, E.V. Dorzhieva, IJEFI, 3S, 238 (2015) 